\title{
A leakage current estimation based on thermal image of polymer insulator
}

\author{
Darwison ${ }^{1}$, Syukri Arief ${ }^{2}$, Hairul Abral ${ }^{3}$, Ariadi Hazmi ${ }^{4}$ M. H. Ahmad ${ }^{5}$, Eka Putra Waldi ${ }^{6}$, \\ Rudy Fernandez \\ 1,4,6,7 Department of Electrical Engineering, Universitas Andalas, Indonesia \\ ${ }^{1,2}$ Department of Chemistry, Universitas Andalas, Indonesia \\ ${ }^{3}$ Department of Mechanical Engineering, Universitas Andalas, Indonesia \\ ${ }^{5}$ Institute of High Voltage and High Current, School of Electrical Engineering, Faculty of Engineering, Universiti \\ Teknologi Malaysia, Malaysia
}

\begin{tabular}{l} 
Article Info \\
\hline Article history: \\
Received Mar 9, 2019 \\
Revised Jun 13, 2019 \\
Accepted Jul 5, 2019 \\
\hline
\end{tabular}

\section{Keywords:}

Color detection methods

Leakage currents

Pollution

Polymer insulator

Thermal images

\begin{abstract}
Polymer insulators tend to fail because of the climatic and environmental conditions. The failure occurs when the surface of insulator is contaminated by sea salt or cement dust which lead to partial discharge (PD). Leakage currents will increase by PD that causes deterioration of insulation. To predict the insulation failures, an adaptive neurofuzzy inference system (ANFIS) method using initial color detection processes are proposed to estimate the leakage currents based on the polymer insulator thermal images (infrared signature). In this study, the sodium chloride and kaolin are used as pollutants of the polymer insulator according to IEC 60507 standards. Then, the insulator is tested in the laboratory using AC high voltage applied at $18 \mathrm{kV}$ where the temperature detection is controlled at $26^{\circ} \mathrm{C}$ and $70 \% \mathrm{RH}$ (relative humidity). The percentage of colors (Red, Yellow, and Blue) from the thermal image is measured using the color detection method. Correspond to the color percentage, the ANFIS method predicts leakage currents from polymer insulators. Furthermore, this system interprets measured data from insulators that need to be categorized as Safe, Need Maintenance or Harmful. The final application of the system can be a non-contact tool to predict the polymer insulators used by technicians in the field.
\end{abstract}

Copyright $@ 2019$ Institute of Advanced Engineering and Science. All rights reserved.

\section{Corresponding Author:}

Darwison,

Department of Electrical Engineering,

Universitas Andalas,

Kampus Limau Manis Road, Padang, Indonesia.

Email: ddarwison@gmail.com

\section{INTRODUCTION}

Polymer insulators [1-17] show several advantages over ceramic insulators [18-31] such as lowenergy surfaces that help to maintain hydrophobic surfaces. However, insulators in electricity transmission may not function properly even though the age of isolation is still within reasonable limits. This can be occured due to insulators work under different climatic and environmental conditions such as near the beach or a cement plant. The surface of this polluted insulator [1, 6, 10-12, 14-16, 18-20, 22-31] can create partial discharge (PD) [13, 22, 28, 32] and lead to increased leakage current [2-7, 9-16, 21-22, 26-29, 31-32].

As leakage current is getting increased, it causes a decrease in the quality of the insulator and shortens the lifetime of the insulator in the insulation system. If an intensity of the contamination layer on the insulating surface increases for a long time, the leakage current may cause heat and even leads to surface flashover [1-2, 6-8, 10-12, 14, 20, 25-27, 29]. 
Different methods have been applied to study leakage current and PD behavior of contaminated surfaces [30] on insulators [10, 20-25, 31]. However, a correlation study between leakage current and thermal behavior of insulator surfaces has not been found in the literature [6]. In this proposed method, a thermal camera $[2,8,18-19,28,32]$ is used to capture an image of thermal surface of the insulator and then the thermal image is interpreted using a color detection method. By calculating the percentage of color which is used as input in the ANFIS method to predict [1, 4, 26-27, 29] the leakage currents of polymer insulators in a non-contact manner. A MatLab program has been developed in the system to classify the condition of the insulator into category: Safe, Maintenance and Dangerous state. Based on the category result, a field technician can make a decision whether necessary or not to replace the insulator.

\section{RESEARCH METHOD}

\subsection{Test Objects}

A $20 \mathrm{kV}$ polymer insulator was used in this work as illustrated in Figure 1. The insulator tested was hung vertically $[10,12,14,19,21,23-25,31]$ facing the thermal camera in a space $(1.2 \times 0.5 \times 0.7$ [m3] $)$ as shown in Figure 2. The test voltage was $18 \mathrm{kVrms}$ at a frequency of $50 \mathrm{~Hz}$. Room humidity was at $70 \% \mathrm{RH}$ and temperature was $26^{\circ} \mathrm{C}$. The test was carried out in accordance to IEC 60507; clean fog test procedure. Before testing, the insulator surface was cleaned with isopropyl alcohol and rinsed with distilled water to remove dirt and grease [27]. Typical beach salt pollution was produced by creating a surface layer of contaminants on the insulator. Contaminants were formed from $\mathrm{NaCl}$ with 40 grams of kaolin mixed with 1 liter of water. The $\mathrm{NaCl}$ salt concentration gives a density of equivalent salt deposits (ESDD) in $\mathrm{mg} / \mathrm{cm} 2$ with a heavily contaminated value [27]. Liquid potassium sulfate-producing containers were used to maintain relative humidity in the fog room. The fog producing container was connected by two tubes to the polymer insulator test container. Relative humidity and temperature in the test container were maintained using an Arduino microcontroller with a temperature sensor, humidity sensor, two sets of 12 VDC fan for air circulation, a 12 VDC motor for potassium sulfate stirrer and a heater.

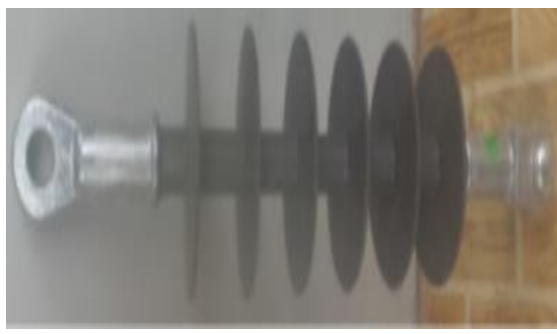

(a)

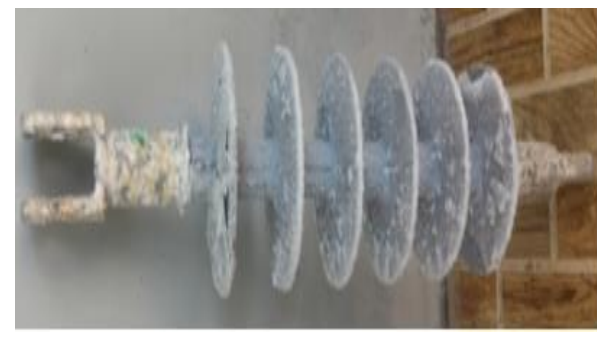

(b)

Figure 1. The polymer insulator of $20 \mathrm{kV}$ under level of (a) clean and (b) contaminated

\subsection{Measurement System}

As shown in Figure 2 that the voltage regulator was connected to the input part of the High Voltage Transformer (HVT) which was used as a test voltage regulator applied to the polymer insulator. High Voltage Amplifier in the form of (HVT) was used as a high voltage generator which was used as a test voltage [26] with a ratio of 1: 2000 Volt (peak to peak). An oscilloscope (Tektronix, DPO 5104) was used to display the input voltage via a voltage probe (Tektronix, P6015A) as well as the leakage current through the insulator and also the PD activity was recorded by the PD detector. The high voltage of the transformer through $25 \mathrm{M} \Omega$ series resistance enters the $4000 \mathrm{pF}$ insulator and capacitor filling. If there was a PD on the insulator then the capacitor has removed the charge so that the PD detector would detect the PD occurrences and then the PD activity was displayed in the oscilloscope. Voltage probe with a ratio of 1: $1000 \mathrm{~V}$ was used as a working voltage/test detector applied during testing. Leakage current was calculated based on a voltage read by an oscilloscope on a $47 \mathrm{k} \Omega$ shunt resistor $[6,22,27]$ which was in series with the insulator. The purpose of using a $47 \mathrm{k} \Omega$ sampling resistor was that the leakage current signal can be detected properly for a high voltage range of $10 \mathrm{kV}$ to $24 \mathrm{kV}$ [21]. Thermal camera from Thermograph FLIR A-600 series was used to capture thermal images and then stored and processed to predict leakage currents with ANFIS intelligent systems via laptop [27]. 


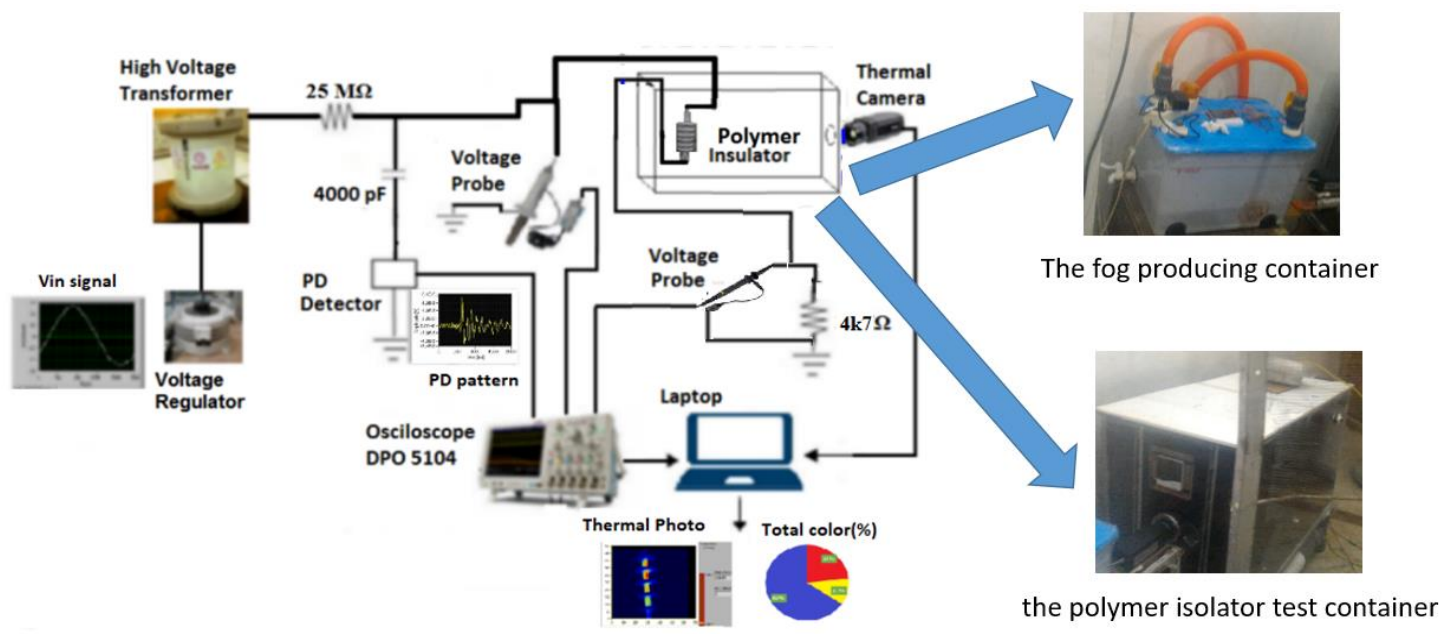

Figure 2. A schematic diagram of the experimental setup

\subsection{ANFIS System}

A typical ANFIS architecture where each circle shows a fixed node and each square indicates an adaptive node as shown in Figure 3. So the basic system of rules has two rules if-then the Takagi-Sugeno type as follows:

Rule $\mathrm{i}$ : if $\mathrm{x}$ is $\mathrm{Ai}$ and $\mathrm{y}$ is $\mathrm{Bi}$, then $\mathrm{fi}=$ pix+qiy+ri, $\mathrm{i}=1,2$.

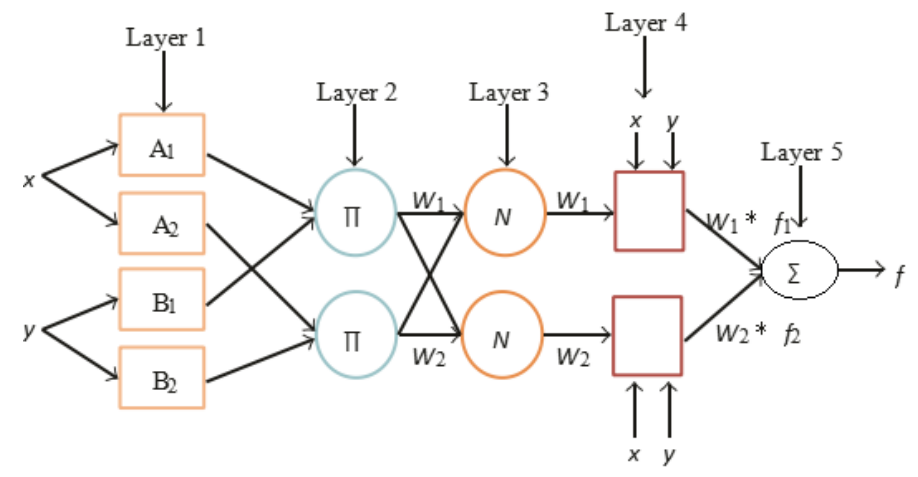

Figure 1. Architecture of typical ANFIS

In Figure 3. there are five process layers, namely:

Layer 1: fuzzification process

Each node $i$ is an adaptive node and the output is given by

$$
\begin{aligned}
& \mathrm{O} 1, \mathrm{i}=\mu \mathrm{Ai}(\mathrm{x}), \text { for } \mathrm{i}=1,2, \text { or } \\
& \mathrm{O} 1, \mathrm{i}=\mu \mathrm{Bi}-2(\mathrm{y}), \text { for } \mathrm{i}=3,4,
\end{aligned}
$$

The membership function for A can be in the form of the appropriate parameterized membership function, such as the generalized bell function.

$$
\mu A(x)=\frac{1}{1+\left|\left(x-c_{i}\right) / a_{i}\right|^{2 b i}}
$$

Layer 2: product layer 
Each node is a fixed node labeled $\pi$ that determines the activation strength (firing strength) of each rule as a product of all incoming inputs,

$$
\mathrm{O} 2, \mathrm{i}=\omega \mathrm{i}=\mu \mathrm{Ai}(\mathrm{x}) \mu \mathrm{Bi}(\mathrm{y}), \mathrm{i}=1,2
$$

So that

$$
\begin{aligned}
& \omega 1=\mu \mathrm{A} 1(\mathrm{x}) \text { AND } \mu \mathrm{B} 1(\mathrm{y}) \\
& \omega 2=\mu \mathrm{A} 2(\mathrm{x}) \text { AND } \mu \mathrm{B} 2(\mathrm{y})
\end{aligned}
$$

The output in this layer acts as a function of weight

Layer 3: normalization layer

Each $\mathrm{N}$ label circle node is non-adaptive which calculates the ratio between firing strength on the first rule to the total firing strength of all rules.

$$
O_{3, i}=w_{i}=\frac{w_{i}}{w_{1}+w_{2}}, \quad
$$

Layer 4: defuzzification layer

The output of each adaptive node in this layer is

$$
\mathrm{O} 4, \mathrm{i}=\text { wifi }=\text { wi }(\text { pix }+ \text { qiy }+ \text { ri }) \text {, }
$$

where wi is the output on layer 3 and $\{$ pi, qi, ri $\}$ are called as consequence parameter.

Layer 5: total output layer

The Final Layer, the single node in this layer is a fixed node labeled, which calculates the overall output as the sum of all incoming signals.

$$
\text { Overall output }=O_{5, i}=\sum_{i} w_{i} f_{i}=\frac{\sum_{i} w_{i} f_{i}}{\sum_{i} w_{i}}
$$

\section{RESULTS AND ANALYSIS}

With a heavily polluted insulator at $18 \mathrm{kV}$ AC applied high voltage for about 1 hour (529 data files), it would produce thermal on the surface of the insulator against time in the test container at $70 \% \mathrm{RH}$ and temperature of $26^{\circ} \mathrm{C}$. Thermal colors of the surface of the insulator were grouped into 3 main colors: blue $\left(303.4^{0} \mathrm{~K} \leq \mathrm{x} \leq 304^{0} \mathrm{~K}\right)$, yellow $\left(304^{0} \mathrm{~K} \leq \mathrm{x} \leq 306.5^{0} \mathrm{~K}\right)$ and red $\left(>306.5^{0} \mathrm{~K}\right)$.

Figure $4 \mathrm{a}$ shows the test results in the form of thermal photos of polymer insulators which are proportional to the percentage of thermal colors (Figure 4b) and thermal distribution (Figure 4c).

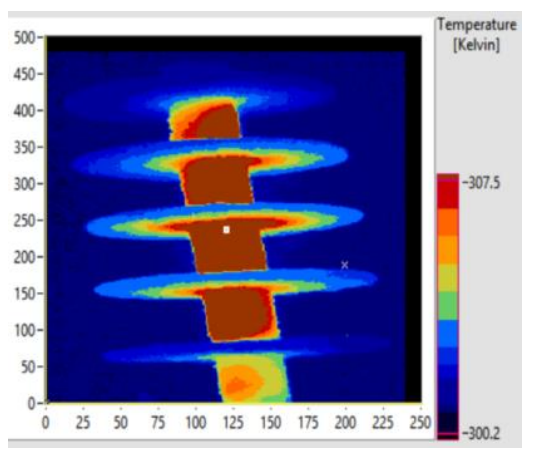

(a)

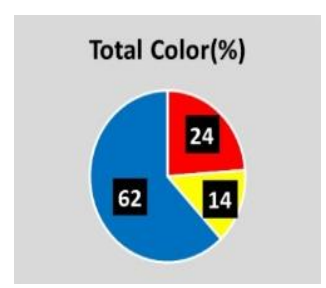

(b)

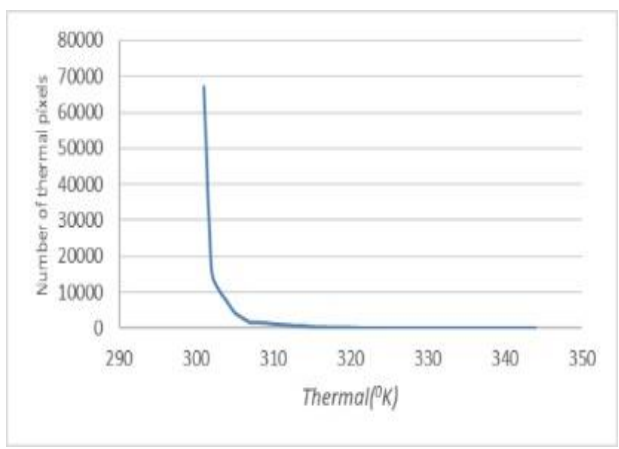

(c)

Figure 4. Testing of heavy pollutant isolators (a) Thermal Photo Zoom (b) Color Percentage (c) Graph of Thermal vs Number of thermal pixels 
Based on the thermal photograph of the insulator surface, the red color is wider in proportion to the thermal rise. This can occur because the ridge can accelerate the greater red color of the surface of the insulator or the higher the thermal peak of the polymer insulator as shown in Figure 5.
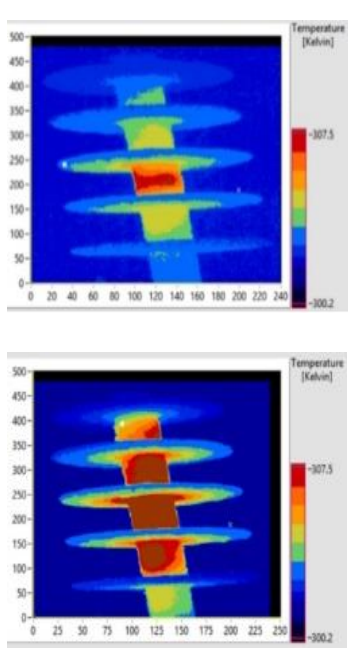

(a)
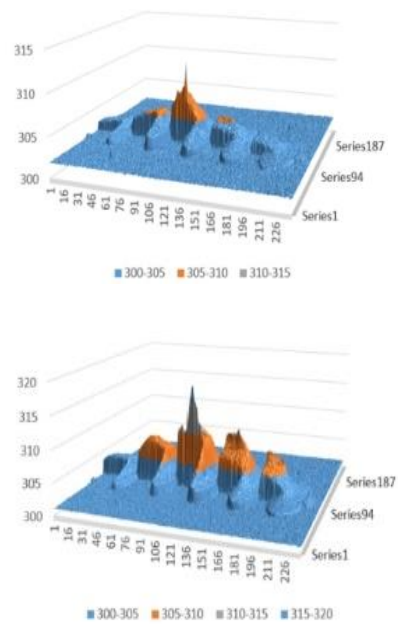

(b)
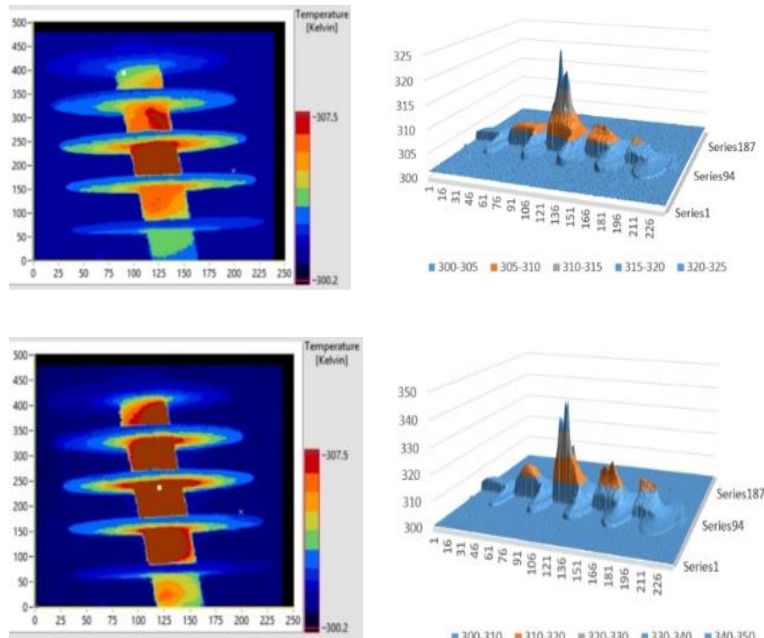

(c)

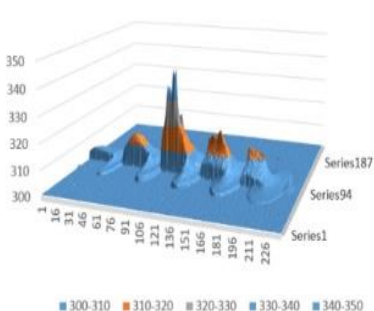

(d)

Figure 5. Thermal photos and 3-dimensional surface images of insulators for leakage current (a) small $(4.2 \mathrm{~mA})(\mathrm{b})$ medium $(14 \mathrm{~mA})(\mathrm{c})$ high $(24 \mathrm{~mA})(\mathrm{d})$ very high $(47 \mathrm{~mA})$

\subsection{Color Detection Method}

By using the color detection method with the MATLAB programming language, the thermal image of the insulator area was shown in Figure 5a with 175,488 (384 x 457) pixels. The first process of Figure 5a as the original image is stored in the jpg extension and named as isolatorsmall.jpg as shown in Figure 6a. Then, the color detection process approaches red color with the following equation: if (im (i, j, 1) > $100 \& \&$ $\mathrm{im}(\mathrm{i}, \mathrm{j}, 2)<90 \& \& \mathrm{im}(\mathrm{i}, \mathrm{j}, 3)<90)$ with results as shown in Figure 6b. Furthermore, Figure $6 \mathrm{~b}$ is stored in the png extension, which was named as isolatorsmall.png. After that, it was done to return the results in Figure $6 \mathrm{~b}$ to a binary image where the red pixels were replaced with white and the others (which are not red pixels) are replaced with black as shown in Figure $6 \mathrm{c}$ with an area of 381.405 (541 x 705) pixels. Binary images were needed to convert RGB images into binary images (black $=0$ and white $=1$ ). Finally, the binary image was converted to a binary image negation as in Figure 6d, resulting in a red area of 3,374 pixels.

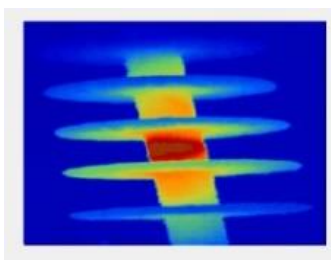

(a)

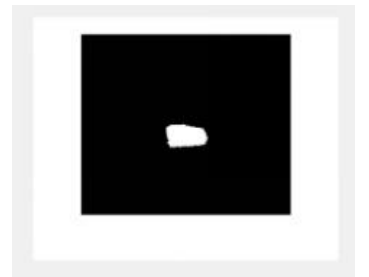

(b)

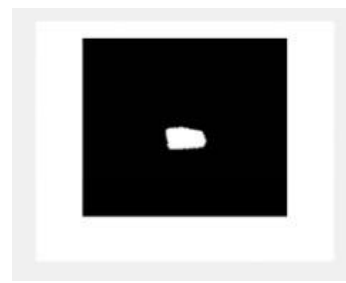

(c)

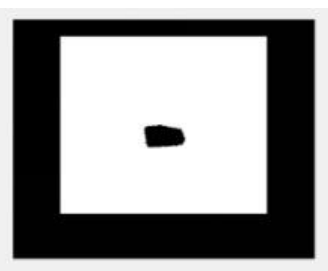

(d)

Figure 6. Detect the red color of the insulator thermal image (a) the original image (b) the color detection results are close to red (c) the results of the binary image (d) the result of the binary image negation

In the same way as Figure 6 , the yellow area was calculated by the equation if (im (i, j, 1)> $100 \& \&$ im (i, j, 2)> $100 \& \&$ im $(i, j, 3)<90)$ which equivalent to 15,557 pixels as shown in Figure 7. Meanwhile, the color area of the insulator as shown in Figure 8 covers an area of 74,519 pixels with the percentage of thermal insulator color as plotted in Figure 9 by using the formula; the area of blue $=$ the area of the insulator - (red area + yellow area). 


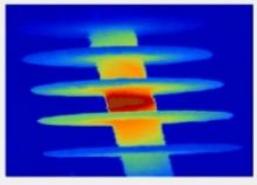

(a)

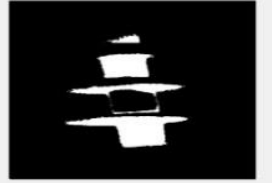

(b)

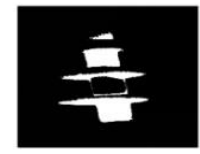

(c)

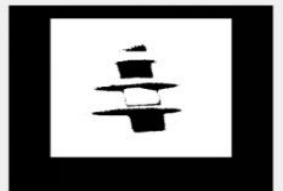

(d)

Figure 7. Detect yellow color of insulator thermal image (a) original image

(b) color detection results are approaching yellow (c) binary image results (d) binary image negation results

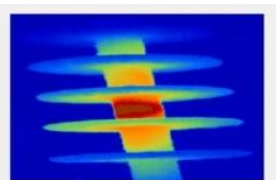

(a)

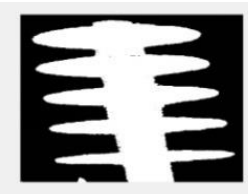

(b)

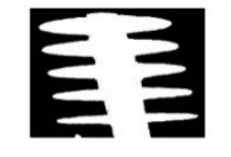

(c)

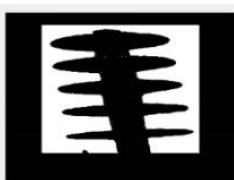

(d)

Figure 8. Color detection of insulator thermal images (a) original image (b) the result of color detection approaching the color of the insulator (c) the results of binary images (d) the results of binary image negation

The color detection method above is based on the Otsu algorithm [19] so that the thermal color percentage of the insulator surface is obtained as shown in Figure 9.

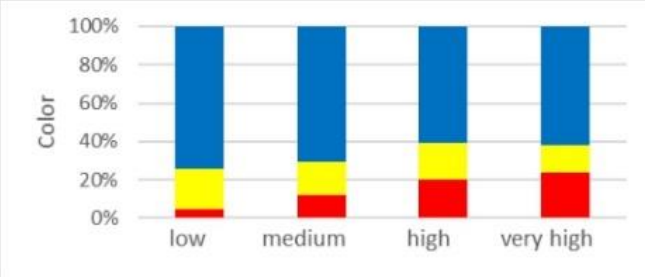

Figure 9. Thermal percentage

In the thermal percentage for the four thermal conditions of the surface of the insulator, if the greater the percentage of red then on the contrary, the smaller the percentage of blue as shown in Figure 9. Percentage of yellow remains, this means that PD activity in Figure 10 is still large within 1 hour thereby resulting in the hotter surface of the insulator thus increasing the leakage current as shown in Figure 11. The heat from the surface of the insulator disappears and the dry band has formed because the flow of leakage current has caused water vapor to evaporate from the surface of the insulator [14]. If the dry-band discharge is continuous, the surface becomes more porous which in itself reduces hydrophobicity and partial expansion of the discharge (PD) during some dry-bands that eventually produce flashover [15]. With contamination deposition on the surface of the insulator, the more influence on the flow of leakage current would occur due to hydrophobic reduction [22].

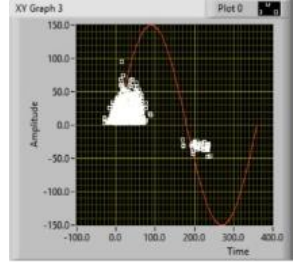

(a)

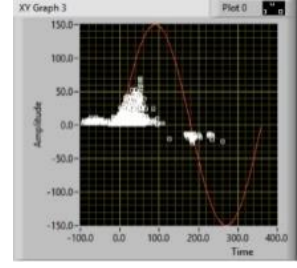

(b)

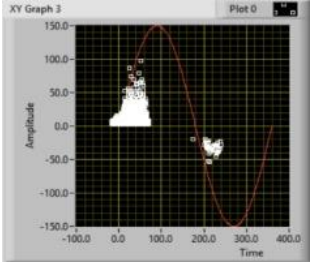

(c)

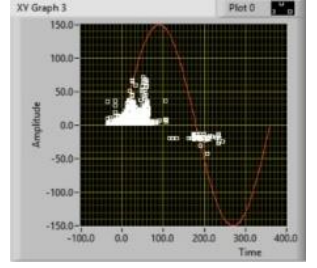

(d)

Figure 10. PD patterns at leakage current (a) $4.2 \mathrm{~mA}$ (b) $14 \mathrm{~mA}$ (c) $24 \mathrm{~mA}$ (d) $47 \mathrm{~mA}$ 


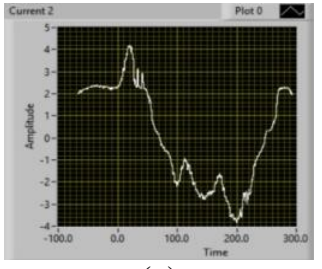

(a)

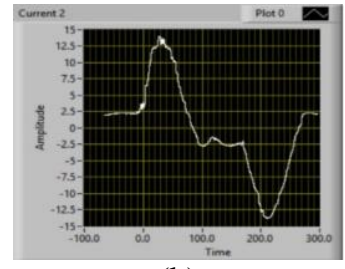

(b)

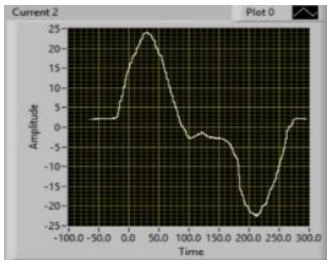

(c)

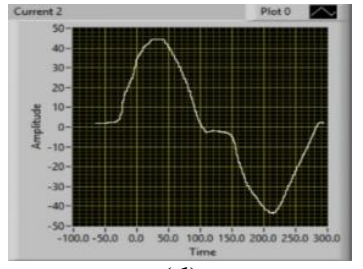

(d)

Figure 11. Classification of leakage current (a) $4.2 \mathrm{~mA}$ (b) $14 \mathrm{~mA}$ (c) $24 \mathrm{~mA}$ (d) $47 \mathrm{~mA}$

With the increasing amount of leakage current as shown in Figure 11, the smaller the phase difference between the test voltage and the leakage current, the more resistive it would be [28] which is shown in Figure 12. As long as the surface of the insulator is clean, the leakage current shows the behavior of the RC network (the leakage current leads the test voltage by the phase angle of around 70 degrees). Similar behavior is also shown during the condition of dry polluted surfaces. Therefore, when the insulator is dry, regardless of the pollutant layer, the insulator behaves like a high impedance RC network, which allows a very low flow of leakage current, $<1 \mathrm{~mA}$ [10]. Figure 12a shows the test of the net isolator with a large enough phase difference between the test voltage and the leakage current at $71 \% \mathrm{RH}$ at $26.4{ }^{\circ} \mathrm{C}$ with a test voltage of $20 \mathrm{kV}$ which produces a leakage current of $\pm 1.5 \mathrm{~mA}$. When the insulator is wet and lightly polished, a significant decrease in phase angle [14] (about 30 degrees). This clearly shows that the resistance of the insulator surface is greatly reduced during wet conditions and the leakage current increases when it is resistive [10]. When the insulators are polished at a given high voltage, the conductivity of the surface where the electric field changes from capacitive to resistive [16]. Figure $12 \mathrm{~b}$ shows the test of heavy polluted insulators at $70 \% \mathrm{RH}$, and temperature of $26^{\circ} \mathrm{C}$ with a test voltage of $18 \mathrm{kV}$ and the test time has taken about 40 minutes so that the surface of the insulator has dried which results in a leakage current of $4.2 \mathrm{~mA}$. During short use and long arc formation, and the surface is heavily polluted and wet, phase angle values have become as low as 5 to 15 degrees [10]. As with the test in Figure 13b, Figure 12c shows a small phase difference with a leakage current of $47 \mathrm{~mA}$ at the instantaneous time of 6.2 minutes of the initial test. The graph of leakage current during the test has decrease with the dry rate of the insulator surface at a fixed relative humidity of $70 \%$ and temperature of $26^{\circ} \mathrm{C}$ as shown in Figure 13. Along with the decreasing leakage current which has been identified to be directly related to the decreasing thermal surface of the insulator, thus PD activity has also getting smaller at the end of the test.

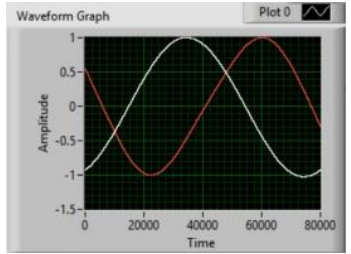

(a)

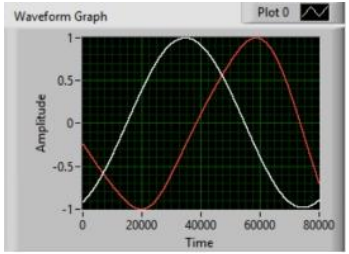

(b)

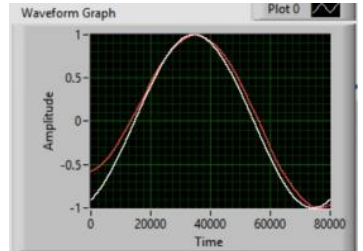

(c)

Figure 12. Phase classification of the leakage current and reference voltage of the insulator (a) clean (b) pollutants at $4.2 \mathrm{~mA}$ leakage current (c) pollutants at $47 \mathrm{~mA}$ leakage current

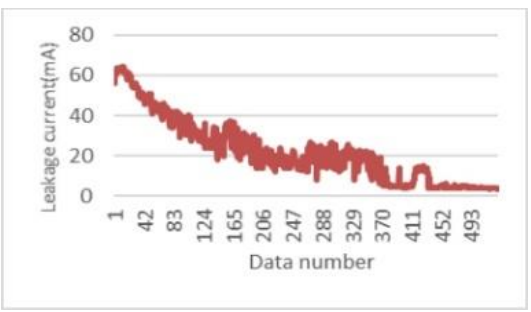

(a)

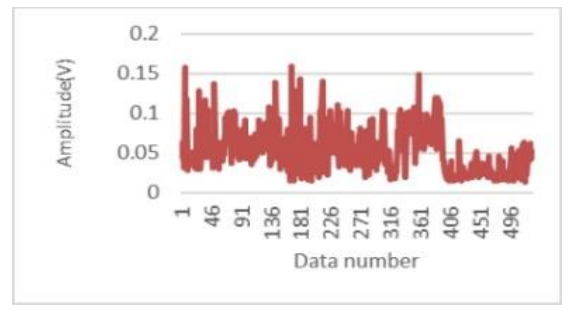

(b)

Figure 13 . Heavy polluted insulator at $70 \% \mathrm{RH}$, temperature of $26{ }^{\circ} \mathrm{C}$ and $18 \mathrm{kV}$ test voltage (a) leakage current (b) PD 
When the humidity is high, the insulator becomes moist, thereby causing PD to occur on the other hand rising the leakage current. In addition, the peak value of the leakage current from the polymer insulator tends to increase with the increase in relative humidity and the increased pollutants [23].

\subsection{Grouping of Leakage Current}

Leakage currents are classified into 3 stages, which are secure $0 \div 50 \mathrm{~mA}(0 \div 24$ minutes $)$, forecast $50 \div 200 \mathrm{~mA}(24 \div 48$ minutes) and danger $>200 \mathrm{~mA}$ (after 48 minutes). Flashover occurs at the danger stage so the contamination flashover must be prevented as soon as possible during the secure stage [29]. To avoid flashover, the condition of the insulator detected through thermal images associated with leakage currents at the secure stage can be classified into 3 categories of categories in Figure 14, namely;

a) The condition is secure if the length (number of lengths) $\leq 0.5$ and width $>0.04$ the surface of the insulator is reddish.

b) Maintenance is needed if the length (number of lengths) ranges from $>0.5$ to $\leq 0.67$ and width $>0.04$ the surface of the insulator is reddish.

c) Danger if the length (number of lengths) ranges from $>0.67$ to $\leq 0.83$ and the width of $\geq 0.02(0.25$ $\mathrm{mm}$ ) the insulator surface is reddish.

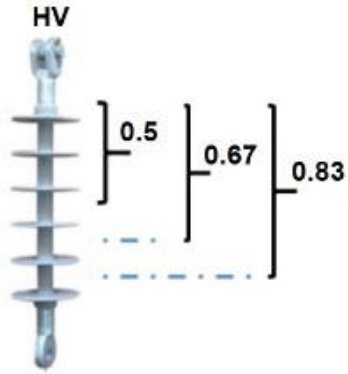

Figure 14. Leakage currents are classified into 3 categories

The length and width of the reddish insulator surface of Figure 5 based on the color detection method are like Table 1.

Table 1. Data on the Length and Width of the Insulator Surface are Reddish

\begin{tabular}{cccc}
\hline \multirow{2}{*}{ Thermal } & Song & Wide & Category \\
& 0,14 & 0,2 & Secure, length $\leq 0,5$ \\
small & 0,5 & 0,14 & Secure, length $\leq 0,5$ \\
medium & 0,7 & 0,1 & Danger, length $>0,67$ \\
high & 0,75 & 0,16 & Danger, length $>0,67$ \\
Very high & &
\end{tabular}

Based on Table 1, it can be concluded that when the thermal is small (4.2 mA current leakage) and moderate (14 mA leakage current) includes a safe while the thermal category is quite large ( $24 \mathrm{~mA}$ leakage current) and large (47 mA leakage current) is considered dangerous. When thermal insulators are categorized as dangerous because the leakage current is close to $50 \mathrm{~mA}$ [29]. Guided by the classification of leaky currents [29], in experiments with high-voltage surface insulators and tests conducted for more than 48 minutes so that flashover occurs. However, the flashover does not occur because the leakage current is getting smaller because the thermal surface of the insulator is also getting smaller. This is because when testing the relative humidity $(\mathrm{RH})$ the insulator surface cannot be wetter with an $18 \mathrm{kV}$ test voltage. Although one of the factors that will make flashovers occur when the insulator surface is very polluted.

\subsection{Forecasts of Leakage Current with ANFIS}

By using combined fuzzy and neural network (ANFIS) method, the leakage current of polymer insulator can be estimated with the ANFIS input data namely arusbocor.dat as shown in Table 2. 
Table 2. Percentage of Color Data and Output of Insulator Leakage Current

\begin{tabular}{ccccc}
\hline \multirow{2}{*}{ No. } & \multicolumn{3}{c}{ Thermal images (\%) } & Leakage \\
\cline { 2 - 4 } 1 & Red & Yellow & Blue & current $(\mathrm{mA})$ \\
1 & 0 & 0 & 100 & 0.15 \\
2 & 3 & 17 & 80 & 7.99 \\
3 & 6 & 22 & 72 & 11.64 \\
4 & 15 & 19 & 66 & 17.03 \\
5 & 21 & 21 & 58 & 35.50 \\
6 & 26 & 31 & 43 & 51.66 \\
\hline
\end{tabular}

ANFIS has resulted minimum RMSE training $=0.000124677$ which requires 27 neurons to reach a value close to zero [24] as shown in Figure 15.
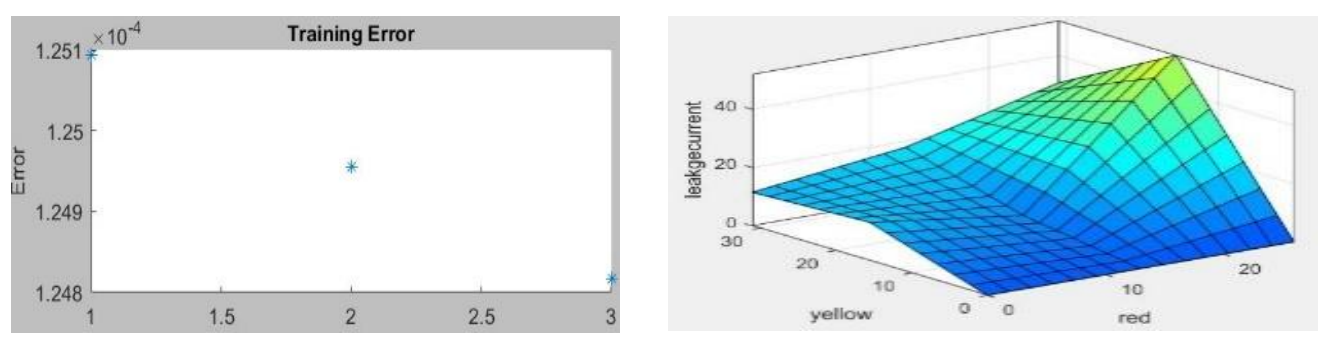

Figure 15. ANFIS Program (a) RMSE training (b) FIS resulted

The results obtained are appropriate and the forecasted leakage currents in heavy polluted insulators is $23.7491 \mathrm{~mA}$ at percentage of red color $(17 \%)$, yellow color $(20 \%)$ and blue color $(63 \%)$ is shown in Figure 16.

In addition, Sugeno fuzzy program has been made by using ANFIS as typed accordingly to 'arusbocor_anfis' then MATLAB would create FIS. Furthermore, the thermal percentage input using evalfis instruction was tested and presented in Figure 14 as well as its estimated leakage current values.

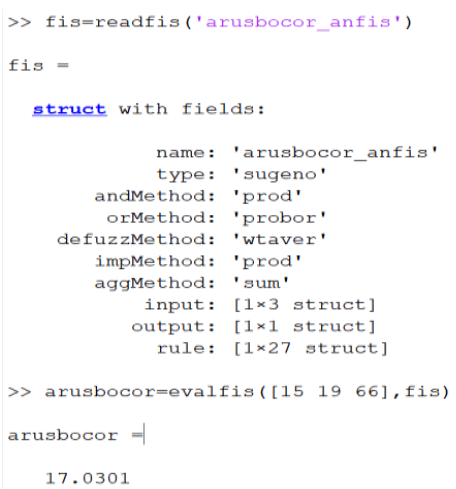

(a)

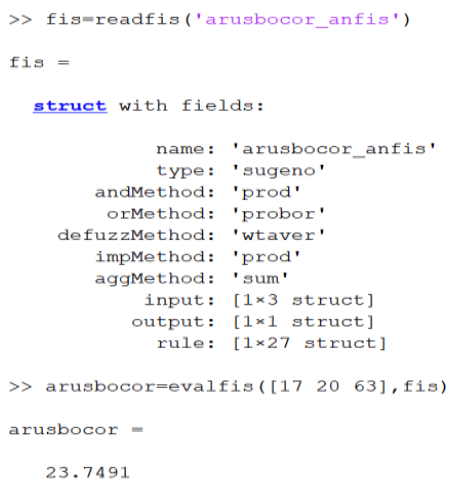

(b)

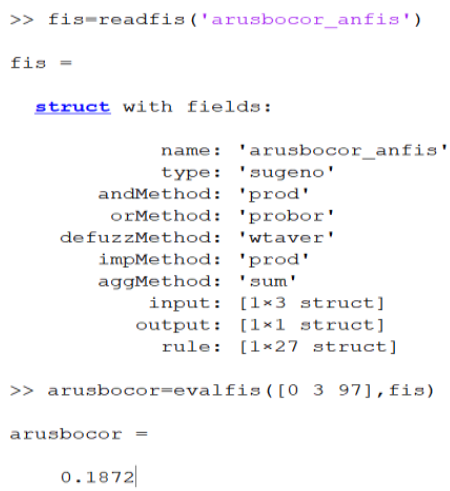

(c)

Figure 16. Evalfis instruction (a) leakage current is obtained according to training

(b) tested in the form of forecasted leakage current and (c) forecasted leakage current of the clean insulator

\section{CONCLUSION}

Pre-processed uses a color detection method for images of thermal polymer insulators that will speed up the process of estimating leakage currents in a non-contact manner. Pre-processing produces a percentage of red, yellow and blue as input from the ANFIS method. In line with that, it is necessary to classify leakage currents to determine the classification of insulators in the Secure, Forecast or Danger stages. For the classification of the Secure stage (current leakage $<50 \mathrm{~mA}$ ) it is also necessary to classify leakage isolator currents in the category of Safe, Maintenance or Danger. Safe stage classification with Maintenance and Danger categories is the time that technicians can use to prevent flahover from insulators. This time it 
can be used by technicians to clean insulators from pollutants. The leakage current forecasting based on the thermal image of polymer insulator using ANFIS method was successfully applied and the ANFIS method can speed up the recognizing process of the leakage current value with an acceptable accuracy.

\section{ACKNOWLEDGEMENTS}

This Research was supported by Direktorat Riset dan Pengabdian Masyarakat Direktorat Jenderal Penguatan Riset dan Pengembangan, Kementerian Riset, Teknologi dan Pendidikan Tinggi skema Penelitian Disertasi Doktor (PDD) Tahun Anggaran 2017 Sesuai dengan Kontrak Penelitian Nomor: 059/SP2H/LT/DRPM/IV/2017 Tanggal 3 April 2017. Tahun Anggaran 2017 Indonesia.

\section{REFERENCES}

[1] G. E. Asimakopoulou, V. T. Kontargyri, G. J. Tsekouras, C. N. Elias, F. E. Asimakopoulou, and I. a. Stathopulos, "A fuzzy logic optimization methodology for the estimation of the critical flashover voltage on insulators," Electr. Power Syst. Res., vol. 81, no. 2, pp. 580-588, 2011.

[2] Alok Ranjan Verma and B. Subba Reddy, "Accelerated aging studies of silicon-rubber based polymeric insulators used for HV transmission lines", Polymer Testing, vol.62, pp.124-131, 2017

[3] Alok Ranjan Verma and B. Subba Reddy," Aging studies on polymeric insulators under DC stress with controlled climatic conditions", Polymer Testing, vol.68, pp.185-192, 2018.

[4] Nameer Al Khafaf and Ayman El-Hag,"Bayesian Regularization of neural network to predict leakage current in a Salt Fog Environment”, IEEE Trans. Dielectr. Electr. Insul., vol. 25, no. 2, pp. 686-693, 2018.

[5] D. Pylarinos, "Discharges Classification using Genetic Algorithms and Feature Selection Algorithms on Time and Frequency Domain Data Extracted from Leakage Current Measurements," ETASR - Engineering, Technology \& Applied Science Research, vol. 3, no. 6, pp. 544-548, 2013.

[6] R. Boudissa, S. Djafri, A. Haddad, R. Belaicha, and R. Bearsch, "Effect of insulator shape on surface discharges and flashover under polluted conditions," IEEE Trans. Dielectr. Electr. Insul., vol. 12, no. 3, pp. 429-437, 2005.

[7] A.F.Hamed, L.S.Nasrat, M.A.Hamid and M.A.Hamid, "Enhancement of Flashover Voltage for Polymer Nanocomposities in High Voltage Applications", International Journal of Electrical Engineering \& Technology, vol.9, no.6, pp.24-34, 2018.

[8] Jianguo Wanga, Xiong Xiaoa, Yadong Fana, Li Caia, Yao Tonga, Zhangquan Raob and Zhen Huang, "Interface defect detection for composite insulators based on infrared thermography axial temperature method", Infrared Physics \& Technology, vol.93, pp.232-239, 2018.

[9] Alok Ranjan Verma, Subba Reddy B., "Interpretation of surface degradation on polymeric insulators", Engineering Failure Analysis, vol.95, pp.214-225, 2019.

[10] S. Chandrasekar, C. Kalaivanan, A. Cavallini, and G. Montanari, "Investigations on leakage current and phase angle characteristics of porcelain and polymeric insulator under contaminated conditions," IEEE Trans. Dielectr. Electr. Insul., vol. 16, no. 2, pp. 574-583, 2009.

[11] Iman Ahmadi-Joneidi, Amir Abbas Shayegani-Akmal and Hossein Mohseni, "Leakage current analysis of polymeric insulators under uniform and non-uniform pollution conditions", IET Generation, Transmission \& Distribution, vol.11, no.11, pp.2947-2957, 2017.

[12] D. Pylarinos, K. Siderakis, and E. Pyrgioti, "Measuring and Analyzing Leakage Current for,"Rev. Adv. Mater. Sci., vol. 29, pp. 31-53, 2011.

[13] Xin Zhang, Alasdair Bruce, Simon Rowland, Vladimir Terzija and Siqi Bu, "Modeling the Development of Low Current Arcs and Arc Resistance Simulation”, IEEE Trans. Dielectr. Electr. Insul., vol. 25, no. 6, pp. 2049-2057, 2018.

[14] M. H. Samimi, A. H. Mostajabi, I. Ahmadi-Joneidi, A. A. Shayegani-Akmal, and H. Mohseni, "Performance Evaluation of Insulators Using Flashover Voltage and Leakage Current," Electr. Power Components Syst., vol. 41, no. 2, pp. 221-233, 2013.

[15] I. Ahmadi-Joneidi, A. Majzoobi, A. Shayegani-Akmal, H. Mohseni, and J. Jadidian, "Aging evaluation of silicone rubber insulators using leakage current and flashover voltage analysis," IEEE Trans. Dielectr. Electr. Insul., vol. 20, no. 1, pp. 212-220, 2013.

[16] X. Guoxiang and P. B. McGrath, "Electrical and thermal analysis of polymer insulator under contaminated surface conditions," Dielectr. Electr. Insul. IEEE Trans., vol. 3, no. 2, pp. 289-298, 1996.

[17] Ali. A. Salem, R. Abd-Rahman, M. S. Kamarudin, H. Ahmed, N.A.M. Jamail, N.A. Othman, M.F.M. Yousof, M. T. Ishak and S. Al-Ameri, "The effect of insulator geometrical profile on electric field distributions", Indonesian Journal of Electrical Engineering and Computer Science, vol.14, no.2, pp.618-627, 2019.

[18] M. I. Mousa, Z. Abdul-Malek, and Z. I. Mousa, "Aging Detection of Glass Disc Insulator by Using Infrared Camera,” Indones. J. Electr. Eng. Comput. Sci., vol. 6, no. 3, p. 520-527, 2017.

[19] L. Jin and D. Zhang, "Contamination Grades Recognition of Ceramic Insulators Using Fused Features of Infrared and Ultraviolet Images," Energies, vol. 8, no. 2, pp. 837-858, 2015.

[20] H. Yang et al., "Effect of profiles on ac contamination flashover performance of large-tonnage suspension disc insulators," IEEE Trans. Dielectr. Electr. Insul., vol. 21, no. 6, pp. 2476-2485, 2014.

[21] P. C. Miao and Z. N. Xu, "Effects of different sample resistances on the insulator leakage current acquisition results," Appl. Mech. Mater., vol. 644-650, pp. 3468-3471, 2014. 
[22] B. Banhthasit, K. Tonmitra, A. Kaewrawang, and A. Suksri, "Evaluating on Effect of HVAC Series with Impulse Excitation Voltage on Porcelain Insulator by Using Rotating Wheel Dip Test," Adv. Mater. Res., vol. 354-355, pp. 159-164, 2011.

[23] J. Jiang, R. Mu, C. Li, and Y. Luo, "High Sensitive FBG Sensor for Equivalent Salt," IEEE Photonics Technology Letters, vol. 27, no. 2, pp. 177-180, 2015.

[24] N. a. Al-Geelani, M. A. M. Piah, Z. Adzis, and M. a. Algeelani, "Hybrid regrouping PSO based wavelet neural networks for characterization of acoustic signals due to surface discharges on H.V. glass insulators," Appl. Soft Comput. J., vol. 13, no. 12, pp. 4622-4632, 2013.

[25] F. Pratomosiwi and Suwarno, "Performance improvement of the ceramic outdoor insulators located at highly polluted environment using room temperature vulcanized silicone rubber coating," Int. J. Electr. Eng. Informatics, vol. 2, no. 1, pp. 15-28, 2010.

[26] V. J. Narayanan, M. Sivakumar, K. Karpagavani, and S. Chandrasekar, "Prediction of Flashover and Pollution Severity of High Voltage Transmission Line Insulators Using Wavelet Transform and Fuzzy C-Means Approach," J. Electr. Eng. Technol., Vol.vol. 9, 2014.

[27] Z. Sahli, a. Mekhaldi, R. Boudissa, and S. Boudrahem, "Prediction parameters of dimensioning of insulators under non-uniform contaminated conditions by multiple regression analysis," Electr. Power Syst. Res., vol. 81, no. 4, pp. 821-829, 2011.

[28] Darwison, S. Arief, H. Abral, A. Hazmi, Aulia and M. H. Ahmad, "Thermal Image , Partial Discharge And Leakage Current Correlation Of Ceramic Insulator Under Different Contamination Level," ARPN J. Eng. Appl. Sci., vol. 12, no. 18, pp. 5235-5240, 2017.

[29] J. Li, W. Sima, C. Sun, and S. a. Sebo, "Use of leakage currents of insulators to determine the stage characteristics of the flashover process and contamination level prediction," IEEE Trans. Dielectr. Electr. Insul., vol. 17, no. 2, pp. 490-501, 2010.

[30] M. I. Mousa, Z. Abdul-Malek, Zainab I. M., "Leakage Current Based Thermal Modeling of Glass Disc Insulator Surface”, Indones. J. Electr. Eng. Comput. Sci., vol. 6, no. 3, p. 504-512, 2017.

[31] Suwarno and A. B. Wibowo, "Increasing the performances of various type outdoor insulators by using RTV silicone rubber coating," Int. J. Electr. Eng. Informatics, vol. 4, no. 4, pp. 608-619, 2012.

[32] E. P. Waldi et al., "Automatic threshold of standard deviation to reject noise in raw data of partial discharges," ARPN J. Eng. Appl. Sci., vol. 12, no. 18, pp. 5319-5324, 2017. 